\title{
Comportamento produtivo e econômico da alface americana em função de diferentes lâminas de água
}

\author{
Joaquim A. de Lima Júnior ${ }^{1}$, Geraldo M. Pereira ${ }^{2}$, Luciano 0 . Geisenhoff ${ }^{3}$, \\ Welligton G. da Silva ${ }^{3}$, Renato C. Vilas-Boas ${ }^{4} \&$ Allan K. S. Lobato ${ }^{5}$
}

\begin{abstract}
RESU M O
Visando às dificuldades encontradas pelo produtor no cultivo da alface (Lactuta sativa L.) americana, cv. Laureau, especificamente quanto à falta de informações técnicas sobre quantidade de água a aplicar, objetivou-se estudar o efeito de diferentes lâminas de água sobre o comportamento produtivo e econômico da alface americana. 0 experimento foi realizado na Universidade Federal de Lavras, no período de outubro a dezembro de 2008, em casa de vegetação. 0 delineamento experimental foi em blocos casualizados, com cinco tratamentos e quatro repetições. Os tratamentos foram constituídos de cinco fatores de evaporação, correspondentes a 0,30,0,60,0,90, 1,20 e 1,50 EVm, baseados na lâmina evaporada de um minitanque. Os resultados permitiram concluir que a máxima produtividade total e comercial, $65.918 \mathrm{~kg} \mathrm{ha}^{-1}$ e $35.544 \mathrm{~kg} \mathrm{ha}^{-1}$, foram estimadas com a aplicação de lâminas equivalentes a 152,1 e $155 \mathrm{~mm}$, respectivamente, correspondentes ao fator de reposição de 92\%; considerando o preço do fator água $\left(R \$ 0,67 \mathrm{~mm}^{-1}\right)$ e o preço da alface americana $\left(R \$ 0,90 \mathrm{~kg}^{-1}\right)$, a lâmina economicamente ótima foi $154 \mathrm{~mm}$, identificando que a eficiência técnica do experimento foi significativamente igual à máxima eficiência econômica.
\end{abstract}

Palavras-chaves: Lactuta sativa L., lâmina econômica, casa de vegetação

\section{Economic and productive behavior of production of crisphead lettuce under different irrigation depths}

\begin{abstract}
With the aim of minimizing the difficulties faced by the producers on cultivating the crisphead lettuce (Lactuta sativa L.), specifically those related to the lack of technical information about the quantity of water to be applied, a study was conducted to determine the economic and productive behavior of crisphead lettuce yielding characteristics. The experiment was carried out at the U niversidade Federal de Lavras, from 0 ctober to December 2008 in greenhouse. A randomized block design with five treatments and four repetitions was adopted. The treatments, consisting of the five respective evaporation factors: 0.30 , $0.60,0.90,1.20$ and $1.50 \mathrm{EVm}$, were done according to an evaporated depth of a reduced pan. The results show ed that the maximum total and commercial yield, 65.918 and $35.544 \mathrm{~kg} \mathrm{ha}^{-1}$, were estimated by applying depths equivalent to 152.1 and $155 \mathrm{~mm}$, respectively, corresponding to $92 \%$ replacement factor; regarding water factor price $\left(R \$ 0.67 \mathrm{~mm}^{-1}\right)$ and crisphead lettuce price $\left(R \$ 0.90 \mathrm{~kg}^{-1}\right)$, the economically optimum depth was $154 \mathrm{~mm}$, which resulted in a commercial yield practically equal to the maximum economical efficiency.
\end{abstract}

Key words: Lactuta sativa L., economic depth, protected environment

${ }^{1}$ D CEE /U FRA - Campus Paragominas, Rod. PA 256, km 06, Bairro N ova Conquista S/N , CP 917, CEP 68625-000, Paragominas, PA. Fone: (91) $3729-4851$. E-mail: joaquim.junior@ufra.edu.br

2 DEG/U FLA. Bolsista do CN Pq. CEP 37200-000, Lavras, MG. Fone: (35) 3829-1389. E-mail: geraldop@ufla.br

3 Doutorando DEG/UFLA. Fone: (35) 3829-1389. E-mail: lucianogeisenhoff@ig.com.br

${ }^{4}$ D outor em Engenharia Agrícola, Rua João Renato de Pádua 65, CEP 37200-000, Lavras, MG . Fone: (35) 3822-5079. E-mail: renatovilasboas@yahoo.com.br

${ }^{5}$ UFRA, Campus Paragominas. Fone: (91) 3729-4851. E-mail: allan.lobato@ufra.edu.br 


\section{INTRODUÇÃO}

A alface (Lactuca sativa L.) é a principal hortaliça folhosa comercializada e consumida pela população brasileira pela facilidade de aquisição e por ser produzida o ano inteiro (Oliveira et al., 2004). Ressalta-se que o volume de alface comercializado na CEAGESP-SP em 2007, foi de 28.389, colocando-a, neste ano, na liderança nacional em comercialização e consumo (Agrianual, 2008).

Dentre os tipos existentes de alface merece destaque o plantio da alface tipo americana, por atender à demanda principalmente das redes "fast foods" da região. Atualmente, no sul de Minas Gerais um grupo de produtores dessa hortaliça tem produzido cerca de 1.000 toneladas brutas mês, apenas para abastecer uma grande rede de lojas (Yuri et al., 2004). A alface americana se diferencia dos demais tipos por apresentar folhas externas de coloração verde-escuro, folhas internas de coloração amarela ou branca, imbricadas, semelhante ao repolho e crocantes, além de maior vida pós-colheita, possibilitando o transporte a longas distâncias (Yuri et al., 2002).

O cultivo em ambiente protegido é uma técnica muito útil para a aquisição de alta produção e de produtos de excelente qualidade, por manter um clima mais propício ao desenvolvimento da cultura ao longo do ano (Segovia et al., 1997); além disso, o cultivo protegido, dependendo menos das condições climáticas, amenizando possíveis infestações de pragas e doenças, passa a aumentar o custo de produção da cultura.

A alface é uma cultura exigente em água, sendo o manejo adequado da irrigação importante não apenas por suprir as necessidades hídricas das plantas mas também por minimizar problemas com doenças e lixiviação de nutrientes, como gastos desnecessários com água e energia (Koetz et al., 2006).

Andrade Júnior \& Klar (1997) obtiveram, estudando o efeito de quatro níveis de irrigação com base na evaporação do Tanque Classe A (ECA) $(0,25 ; 0,50 ; 0,75$ e 1,00), utilizando irrigação por gotejamento na cultura da alface tipo americana, valor máximo para produtividade total de $90 \mathrm{t} \mathrm{ha}^{-1}$, com o nível de irrigação correspondente a $75 \%$ da ECA. Nesta mesma linha de pesquisa Silva et al. (2008), testando diferentes lâminas de irrigação na cultivar Raider-Plus, do tipo americana, também obtiveram a máxima eficiência econômica com aplicação da lâmina de 205,26 mm enquanto a eficiência técnica foi obtida com a lâmina de 208,03 mm. Lima Júnior et al. (2010) obtiveram máximo valor de produtividade total e comercial para a alface americana, cv. Raider Plus, com as lâminas 203,9 mm de 204,3 mm, respectivamente.

A utilização de funções de resposta de culturas constituiu fontes valiosas de informações a serem utilizadas nos modelos de tomada de decisão das empresas agrícolas. A função de produção mostra a quantidade física obtida do produto a partir da quantidade física utilizada dos fatores de produção em determinado período de tempo (Vasconcellos, 2007).

Em termos econômicos a implantação e a operação de sistemas de irrigação envolvem custos elevados e, normalmente, a máxima produtividade física não corresponde à maior receita líquida, devido à natureza complexa da resposta das culturas à irrigação, variabilidade climática e flutuações das condições econômicas (Algozin et al., 1988); logo, para uma empresa agrícola a determinação de aplicação de uma lâmina de água de irrigação que proporcione a maior receita líquida, se torna importante.

A maior parte da literatura nacional indica recomendações genéricas ao produtor sobre pesquisas envolvendo irrigação e fertilizantes, ou seja, objetiva a obtenção de produtividades físicas máximas sem qualquer preocupação com a economicidade. Resultados de pesquisas que embasam essas informações poderão torná-los inviáveis do ponto de vista econômico de vez que, em geral, a máxima produtividade biológica não corresponde com o ponto ótimo econômico.

Objetivou-se, com o presente trabalho, avaliar o efeito de lâminas de irrigação sobre os rendimentos produtivos e econômicos da alface americana em ambiente protegido, na região de Lavras, MG.

\section{Material e MÉTODO}

O experimento foi desenvolvido em casa de vegetação situada na área experimental do Departamento de Engenharia da Universidade Federal de Lavras (DEG/UFLA), no período compreendido entre 03 de outubro a 22 de dezembro de 2008 . A UFLA se situa em Lavras, Sul de Minas Gerais, e está numa altitude média de $910 \mathrm{~m}, 21^{\circ} 14^{\prime}$ latitude Sul e $45^{\circ} 00^{\prime}$ longitude Oeste.

De acordo com a classificação de Köppen (Dantas et al., 2007), a região apresenta um clima Cwa, ou seja, clima temperado chuvoso (mesotérmico), com inverno seco e verão chuvoso, temperatura média do mês mais frio inferior a $18^{\circ} \mathrm{C}$ e superior a $3{ }^{\circ} \mathrm{C}$; no verão a temperatura média do mês mais quente é superior a $22{ }^{\circ} \mathrm{C}$.

A casa de vegetação experimental foi construída com estrutura metálica do tipo teto em arco, apresentando $2,5 \mathrm{~m}$ de pé-direito, 4,0 $\mathrm{m}$ de altura no ponto mais alto, $13 \mathrm{~m}$ de comprimento e $7 \mathrm{~m}$ de largura, coberta com filme de polietileno de baixa densidade transparente, aditivado anti-UV com espessura de $150 \mu$ e as laterais fechadas com tela antiafídeo. $\mathrm{O}$ solo da área experimental foi classificado como Latossolo Vermelho Distroférrico.

Empregou-se o delineamento em blocos casualizados (DBC) com cinco tratamentos e quatro repetições, perfazendo o total de 20 parcelas. Os tratamentos se constituíram de cinco lâminas de água com base na evaporação do minitanque, sendo: W130; W2-60, W3-90; W4-120 e W6-150\% da evaporação do minitanque.

O minitanque tem a forma circular, é construído em chapa galvanizada com $60,5 \mathrm{~cm}$ de diâmetro (50\% do diâmetro do tanque Classe A), 25,4 cm de profundidade e apoiado sobre estrado de madeira com altura de $15 \mathrm{~cm}$ acima do solo. $\mathrm{O}$ minitanque foi instalado no centro de uma das casas de vegetação.

As parcelas experimentais apresentaram as dimensões de 1,20 m de largura e 2,40 m de comprimento, totalizando uma área de $2,88 \mathrm{~m}^{2}$. Quatro linhas de plantas espaçadas $0,30 \mathrm{~m}$ 
entre linhas e $0,30 \mathrm{~m}$ entre plantas, foram utilizadas perfazendo o total de 32 por parcela, considerando-se úteis as plantas das linhas centrais e, dentre elas, se descartando duas plantas no início e duas no final de cada parcela (parcela útil com $0,72 \mathrm{~m}^{2}$ e 8 plantas). Utilizou-se de sistema de irrigação por gotejamento, sendo as linhas laterais compostas por emissores com vazão de $1,76 \mathrm{~L} \mathrm{~h}^{-1}$, DN $16 \mathrm{~mm}$ e distanciadas entre si a 0,30 $\mathrm{m}$, ficando posicionadas na parcela, de forma a atender às duas fileiras de plantas, trabalhando com pressão de serviço em torno de 18 mca.

A lâmina de água aplicada com frequência de dois dias foi calculada considerando-se a porcentagem da evaporação $(\mathrm{K})$ medida no período previsto entre duas irrigações ( 2 dias), de acordo com cada tratamento e a eficiência de aplicação de água do sistema de irrigação, conforme a Eq. 1.

$$
\mathrm{LI}=\frac{\mathrm{EVm} \mathrm{K}}{\mathrm{Ei}}
$$

em que:

L - lâmina de irrigação a ser aplicada em cada tratamento, $\mathrm{mm}$

EVm - evaporação do minitanque medida no período, $\mathrm{mm}$

Ei - eficiência de aplicação de água do sistema $(0,90)$ e $\mathrm{K}=$ fração da evaporação de cada tratamento

Obtiveram-se as diferentes lâminas de irrigação para cada tratamento mediante diferentes tempos de funcionamento das linhas de gotejadores. Este tempo foi obtido a partir da vazão média dos gotejadores, do espaçamento entre plantas e entre linhas de plantio, apresentados na Eq. 2.

$$
\mathrm{Ti}=\frac{\text { LI Sp Slp }}{\mathrm{e} \mathrm{q}}
$$

em que:

Ti - tempo de irrigação para cada tratamento, $h$

U - lâmina de irrigação a ser aplicada no tratamento, $\mathrm{mm}$

$\mathrm{Sp}$ - espaçamento entre plantas, $0,30 \mathrm{~m}$

Slp - espaçamento entre linhas de plantas, $0,30 \mathrm{~m}$

e - número de emissores por planta $(0,5)$ e q = vazão média do gotejador, $1,76 \mathrm{~L} \mathrm{~h}^{-1}$

A cultivar utilizada foi a Laureau, tipo americana. A adubação básica foi realizada vinte e um dias antes do transplantio, cujas quantidades foram aplicadas com base na análise química do solo. Ressalta-se que toda a adubação de cobertura foi realizada via fertirrigação, justamente quando se realizava a aplicação dos tratamentos, sendo utilizados os fertilizantes: nitrato de potássio, nitrato de cálcio e o sulfato de magnésio.

Do transplantio até o início da diferenciação dos tratamentos foram realizadas, durante quatro dias, irrigações, nos cinco tratamentos, totalizando uma lâmina de $151 \mathrm{~mm}$; este procedimento teve como objetivo proporcionar um "pegamento" melhor e a uniformização no desenvolvimento inicial das mudas.
A colheita foi efetivada no dia 21 de dezembro de 2008, quando as plantas atingiram seu máximo desenvolvimento vegetativo, justamente quando as cabeças da alface americana se encontravam bem enfolhadas e compactas. As avaliações foram realizadas imediatamente após a colheita das parcelas úteis.

As variáveis analisadas foram produtividade total e da cabeça comercial. Após a análise de variância pelo teste $\mathrm{F}$, os dados obtidos foram executados nos seus efeitos quando significativos em um nível nominal de significância mínima de 5 e $1 \%$ de probabilidade e ajustados por meio de uma análise de regressão polinomial. Utilizou-se o software Sisvar para Windows, versão 4.0. Visando à obtenção da função de produção utilizou-se a análise de regressão entre a variável dependente (produtividade comercial) e a variável independente (lâmina de água).

O modelo usado foi o polinomial do segundo grau, conforme Eq. 3 .

$$
\mathrm{Y}=\mathrm{a}+\mathrm{bw}+\mathrm{c} \mathrm{w}^{2}
$$

em que:

$\mathrm{Y}$ - produtividade comercial, $\mathrm{kg} \mathrm{ha}^{-1}$

w - lâmina total de água aplicada, $\mathrm{mm}$

a, b e c - parâmetros da equação, tendo como hipóteses que $b>0$ e $c<0$

A lâmina de água a ser aplicada para obtenção da máxima produtividade física é dada por:

$$
\mathrm{W}(\max )=-\frac{\mathrm{b}}{2 \mathrm{c}}
$$

A lâmina de água de maior retorno econômico a ser aplicada deve corresponder a uma produtividade que otimize a lucratividade do experimento. A função do lucro a ser maximizado é dada pela diferença da receita bruta com os custos do fator água, sendo os demais fatores utilizados no sistema produtivo do experimento, mantidos constantes e expressos por:

$$
\mathrm{L}(\mathrm{w})=\mathrm{Py} \mathrm{Y}-\mathrm{Pw} \mathrm{W}-\mathrm{K}
$$

em que:

$\mathrm{L}(\mathrm{w})$ - lucro, $\mathrm{R} \$ \mathrm{ha}^{-1}$

$\mathrm{Pw}$ - preço do fator água, $\mathrm{R} \$ \mathrm{~mm}^{-1} \mathrm{ha}^{-1}$

Py - preço do produto, $\mathrm{R} \$ \mathrm{~kg}^{-1}$

$\mathrm{K}$ - custo dos fatores mantidos constantes no experimento, $\mathrm{R} \$ \mathrm{ha}^{-1}$

O preço do produto $(\mathrm{Py})$ representa o preço na indústria por quilo de alface americana comercial. As indústrias de processamento de alface no Sul de Minas Gerais adquiriram a alface ao preço de $\mathrm{R} \$ 0,90 \mathrm{~kg}^{-1}$ (cotação de junho/2008).

O preço do fator água ( $\mathrm{Pw}$ ) foi estimado considerando-se os custos da energia para o bombeamento e os custos de manutenção e operação do sistema de irrigação. Devido à 
presença constante de variação dos fatores estimadores do preço do fator água, dificultando a estimação dos custos, fixaram-se alguns parâmetros, tais como: método de irrigação por gotejamento com acionamento automático; área: 10.000 $\mathrm{m}^{2}$; número de plantas por hectare (79.262); altura manométrica total de $300 \mathrm{kPa}$ (30 mca); vazão da motobomba de 11,63 $\mathrm{m}^{3} \mathrm{~h}^{-1}$; eficiência do conjunto motobomba de $50 \%$; vida útil do sistema de irrigação de 10 anos e utilização de 4 ciclos de cultura por ano.

Nessas condições o custo do sistema de irrigação foi de R $\$$ 7.172,23 incluído-se, aí, a bomba e o motor monofásico, o tubogotejador, o injetor de fertilizante, o controlador com 6 estações, a chave de partida, válvulas solenóides, a tubulação de sucção e recalque, além das conexões.

$\mathrm{Na}$ estimativa da depreciação do sistema (fator de recuperação de capital), que consiste no custo de substituir o equipamento quando inútil, ou seja, pelo desgaste físico ou mecânico, consideram-se a taxa de juros anual de $10 \%$ e a vida útil do equipamento de 10 anos, chegando-se a um fator de 0,1627 em que, multiplicado a custo do sistema de irrigação, gerou-se o custo de amortização, de $\mathrm{R} \$ 1$ 1.167,23.

O custo de manutenção e de operação do sistema de irrigação foi considerado sobre $2 \%$ do seu valor de aquisição, o que equivale a $\mathrm{R} \$ 143,45 \mathrm{ha}^{-1} \mathrm{ano}^{-1}$ ou $\mathrm{R} \$ 35,86 \mathrm{ha}^{-1}$ por ciclo da cultura ao ano.

Consideraram-se, para obtenção do custo da energia elétrica de bombeamento da água, os seguintes itens: motobomba de 3 cv, irrigação diária de duas horas e seis minutos, com 52 dias de cultivo. $\mathrm{O}$ valor do $\mathrm{kWh}$, fornecido pela concessionária de energia elétrica de Minas Gerais, a CEMIG para o mês de junho de 2008, foi de $\mathrm{R} \$ 0,29$ enquanto o custo total de energia elétrica para o bombeamento foi estimado em $\mathrm{R} \$ 85,86 \mathrm{ha}^{-1}$.

Nesta análise não se considerou o efeito dos fatores mantidos constantes no experimento; logo, foi considerada apenas a influência do custo operacional efetivo, ou seja, o custo de manutenção do sistema de irrigação e o custo da energia consumida no bombeamento de cada tratamento para o cálculo do preço do fator água. Desta forma, o custo operacional efetivo foi calculado somando-se o custo de manutenção e operação do sistema e o custo da energia consumida no bombeamento referente ao tratamento W3; assim, chegou-se ao valor de $\mathrm{R} \$ 121,72 \mathrm{ha}^{-1}$ por ciclo da cultura ${ }^{-1}$.

O custo de $\mathrm{R} \$ 0,67 \mathrm{~mm}^{-1} \mathrm{ha}^{-1}$ de água aplicada foi estimado dividindo-se o custo operacional efetivo pela lâmina total aplicada ao tratamento W3, tomado como referencial para a análise econômica.

Sob a hipótese de que $\mathrm{L}(\mathrm{W})$ tem um máximo e que a água é o único fator variável, tem-se, na Eq. 6:

$$
\frac{\partial \mathrm{L}(\mathrm{w})}{\partial \mathrm{w}}=\mathrm{P}_{\mathrm{y}} \frac{\partial \mathrm{y}}{\partial \mathrm{w}}-\mathrm{P}_{\mathrm{w}}=0
$$

em que:

$(\partial \mathrm{y} / \partial \mathrm{w}) \mathrm{P}_{\mathrm{y}}$ - valor da produtividade física marginal (VPFMa) do fator água, $\mathrm{w}$

$(\partial \mathrm{y} / \partial \mathrm{w})$ - produtividade física marginal (PFMa) do fator água, $\mathrm{w}$
A produtividade física marginal (PFMa) do fator variável é o aumento no produto físico total decorrente do emprego de uma unidade adicional do fator variável. Graficamente, o PFMa representa a inclinação do produto total ou da função de produção em determinado nível do fator variável, ou seja, representado por uma linha tangente à curva de resposta e é um dos indicadores das eficiências técnica e econômica do experimento.

Da Eq. 6 obtém-se o indicador de eficiência econômica, conforme a Eq. (7).

$$
\frac{\partial y}{\partial w}=\frac{P_{w}}{P y}
$$

A Eq. 7 mostra que o lucro se maximizará (considerando-se a água como único fator variável) se a derivada primeira da produtividade em relação à lâmina total de água (produto físico marginal da água) for igual à relação entre os preços do fator (água) e do produto (alface).

Portanto, da expressão (3), obtém-se, na Eq. 8:

$$
\frac{\partial y}{\partial w}=b-2 c w=\frac{P_{w}}{P y}
$$

Da expressão (8) obtém-se a lâmina de irrigação ótima econômica para as condições deste trabalho considerando-se, como fator variável, o total de lâmina de água aplicada com os demais insumos utilizados neste experimento mantidos constantes entre os tratamentos.

\section{RESULTADOS E DISCUSSÃO}

No período de condução do experimento as médias de temperatura e a umidade relativa do ar no interior da casa de vegetação foram de $26,3^{\circ} \mathrm{Ce} 55,4 \%$, respectivamente. O referido valor de temperatura se encontra fora da faixa ótima recomendada por Santana et al. (2009), que relatam a faixa $15 \mathrm{e}$ $20^{\circ} \mathrm{C}$ como adequada ao bom desenvolvimento da alface; no entanto afirmam, ainda, que quando cultivada em regiões de temperatura e luminosidade elevadas esta hortaliça deixa de desenvolver todo o seu potencial genético.

A produtividade total e a comercial foram afetadas significativamente pelo efeito das lâminas de água aplicadas no solo, a 5 e $1 \%$ de probabilidade, pelo teste F (Tabela 1), respectivamente.

No caso da produtividade total e comercial as variações ocorridas podem ser explicadas por uma regressão quadrática, tendo a mesma apresentado maior coeficiente de determinação $\left(\mathrm{R}^{2}\right)$ para as duas variáveis, como visto na Figura 1. A resposta quadrática indica que houve um acréscimo na produtividade total e comercial da cabeça, sempre que as lâminas de irrigação foram aumentadas. O ponto máximo para a produtividade total foi estimado com uma lâmina de $152,1 \mathrm{~mm}$, referente a um fator de reposição (FR) de $91 \%$, equivalente a uma produtividade, para esta variável, de $65.918 \mathrm{~kg} \mathrm{ha}^{-1 ;}$ já para a produtividade da 
Tabela 1. Resumo das análises de variância e de regressão quanto à produtividade total (PT) e a produtividade da cabeça comercial (PCC), em função de diferentes lâminas de irrigação

\begin{tabular}{lrcc}
\hline \multicolumn{1}{c}{ Fonte de } & \multirow{2}{*}{ variação } & G. L. & \multicolumn{2}{c}{ Q. M. } \\
\cline { 3 - 4 }$\quad$ & \multicolumn{1}{c}{ PT } & PCC \\
Lâmina & 4 & $88743343,93^{* *}$ & $44314078,32 * *$ \\
Bloco & 3 & $2300354,18^{\text {ns }}$ & $8763233,73^{\text {ns }}$ \\
Resíduo & 12 & 7225682,22 & 7125704,6 \\
\hline Média (kg ha-1) & - & 61,20 & 32,337 \\
C.V. (\%) & - & 4,39 & 8,25 \\
\hline Linear & 1 & $1555513,6^{\text {ns }}$ & $4094080,22^{* *}$ \\
Quadrática & 1 & $309890120,72^{* *}$ & $142213501,81^{* *}$ \\
Desvios & 2 & $21763870,72^{\text {ns }}$ & $15474365,81^{\text {ns }}$ \\
\hline
\end{tabular}

ns - não significativo pelo teste $F$

${ }^{*} e^{* *}$ - significativos a 5 e $1 \%$ de probabilidade pelo teste $F$, respectivamente

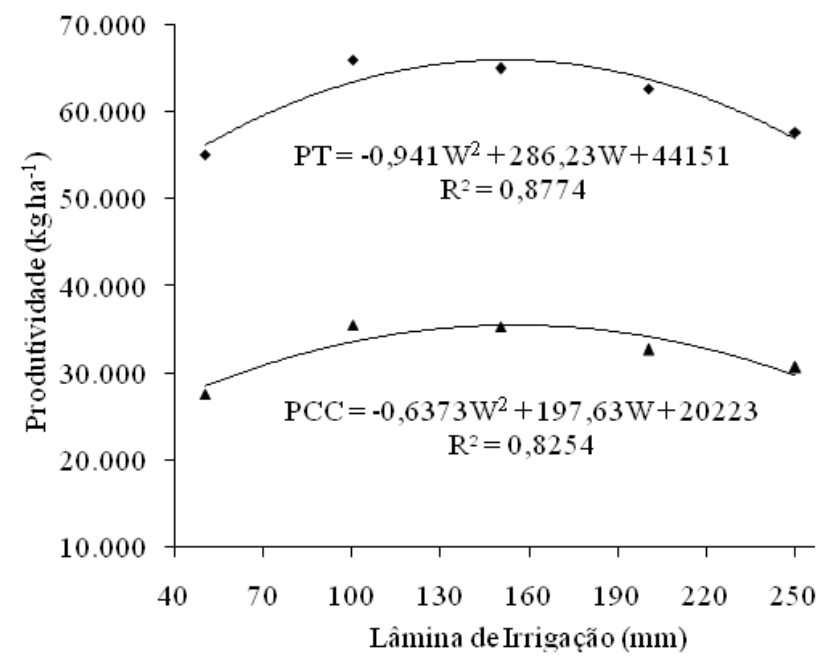

Figura 1. Valores médios observados e estimados da produtividade total (PT) e da cabeça comercial (PCC) de alface americana, em função das lâminas de irrigação

cabeça comercial o ponto máximo foi atingido com a aplicação da lâmina de irrigação de $155 \mathrm{~mm}$ (FR de $93 \%$ ), resultando em uma produtividade, para este parâmetro, de $35.544 \mathrm{~kg} \mathrm{ha}^{-1}$.

Andrade Júnior \& Klar (1997) obtiveram, com a aplicação de 142,3 mm na cultivar Mesa 659, o máximo de produtividade de $90 \mathrm{t} \mathrm{ha}^{-1}$, sob cultivo protegido. Este valor máximo correspondeu às lâminas aplicadas a cada dois dias, referentes a 75\% da evaporação do tanque Classe A. Para valores de lâminas acima de $75 \%$ da evaporação do tanque Classe A ocorreu redução no peso total por planta. Este resultado foi superior ao encontrado neste trabalho podendo ser justificado pela cultivar utilizada pelos autores e também pelas condições climáticas de cada região em que foi realizado o experimento.

Verifica-se que os resultados encontrados neste trabalho estão abaixo dos encontrados por Santos \& Pereira (2004) para produtividade total e comercial da alface americana, valores máximos de 71.180 e $49.380 \mathrm{~kg} \mathrm{ha}^{-1}$, irrigando-se quando a tensão de água no solo, a $15 \mathrm{~cm}$ de profundidade, estava em torno de $15 \mathrm{kPa}$. A lâmina total de irrigação fornecida foi de $152,7 \mathrm{~mm}$.

Lima Júnior et al. (2010) obtiveram o mesmo comportamento quadrático estudando o efeito de cinco lâminas de irrigação sobre a produtividade da alface americana, cv. Raider Plus, sendo obtido valor máximo para produtividade total e comercial com a aplicação $203,9 \mathrm{~mm}$ de $204,3 \mathrm{~mm}$, resultando em produtividades máximas de 65.578 e $35.308 \mathrm{~kg} \mathrm{ha}^{-1}$, respectivamente.

Observa-se, pela curva, redução na PT e na PCC com a aplicação da lâmina de $250,20 \mathrm{~mm}$, correspondente ao tratamento de 1,5 da lâmina evaporada (W5). É provável que este fato tenha ocorrido devido ao excesso de umidade em torno do sistema radicular da planta, dificultando o arejamento e provocando, assim, anomalias de origem fisiológica, bem como a lixiviação de nutrientes. Assim, onera a cultura sem nenhum beneficio representando também um desperdício de água e energia, dois sérios problemas no mundo atual (Filgueira, 2008).

Considerando a hipótese básica de que $\mathrm{L}(\mathrm{w})$ possui valor máximo de acordo com a expressão (5) e que a água é o único fator variável, foram obtidos os produtos físicos marginais da água para o cultivo de alface, o que foi possível derivando-se a função de produtividade comercial e se obtendo, então, o produto físico marginal (PFMa) igualando-se, em seguida, este indicador técnico à relação econômica de preços entre fator lâmina de água e produto alface, como descrito na Eq. 8:

$$
\begin{gathered}
\mathrm{PCC}=-0,6373 \mathrm{~W}^{2}+197,63 \mathrm{~W}+20223 \\
\frac{\partial \mathrm{Y}}{\partial \mathrm{W}}=-1,275 \mathrm{~W}+197,63=\frac{\mathrm{P}_{\mathrm{W}}}{\mathrm{P}_{\mathrm{Y}}}
\end{gathered}
$$

Observa-se, na Tabela 2 que, inicialmente, o PFMa é positivo e decresce sempre que se aumenta a lâmina total de irrigação aplicada ao solo, mantendo-se negativo a partir do pondo máximo da curva de resposta.

Tabela 2. Produto físico marginal da água (PFMa) para as diferentes lâminas de irrigação aplicadas

\begin{tabular}{cc}
\hline Lâminas de irrigação & Produto físico marginal da água \\
50,1 & 133,753 \\
100,1 & 70,003 \\
150,2 & 6,125 \\
200,3 & $-57,753$ \\
250,2 & $-121,375$ \\
\hline
\end{tabular}

Quando o valor do PFMa atinge o valor zero, significa que a lâmina de irrigação aplicada proporcionou a produtividade máxima do experimento, ou seja, a máxima eficiência técnica dos fatores mantidos constantes no experimento, obtida igualandose a primeira derivada a zero $(\mathrm{PFMa}=0)$, representando 35.544 $\mathrm{kg} \mathrm{ha}^{-1} \mathrm{e}$ se aplicando uma lâmina de irrigação de $155 \mathrm{~mm}$. A partir do ponto em que o PFMa apresentou valor nulo, a aplicação de maior lâmina de irrigação o conduziu ao valor de produto físico marginal negativo, indicando ser antieconômico o uso dessa quantidade de água para as condições tecnológicas utilizadas neste experimento, isto é, significa uma super-utilização dos fatores mantidos fixos neste experimento.

A lâmina ótima de irrigação foi calculada igualando-se a expressão do PFMa à relação de preços do fator variável $\left(\mathrm{P}_{\mathrm{w}}\right) \mathrm{e}$ do produto $\left(\mathrm{P}_{\mathrm{y}}\right)$, como expresso na equação (10) obtendo-se, desta forma, a máxima eficiência econômica. 
Na Figura 2 se obtiveram o custo e o valor da produção da alface americana para o mês de dezembro de 2008. Para este mês, a lâmina com que se obteve maior retorno econômico foi de 154 mm (92,3\% de reposição de água), resultando em uma produtividade de $35.544 \mathrm{~kg} \mathrm{ha}^{-1}$, cujos resultados são semelhantes aos encontrados por Lima Júnior et al. (2010), ao obterem a máxima produtividade econômica (35.308 $\left.\mathrm{kg} \mathrm{ha}^{-1}\right)$ com a aplicação de uma lâmina econômica de 203,9 mm, praticamente igual à que traduziu a máxima produtividade física. Ainda segundo Vilas-Boas et al. (2008) e se considerando o preço da água $\left(\mathrm{R} \$ 0,70 \mathrm{~mm}^{-1}\right)$ e o preço da alface do tipo crespa $\left(\mathrm{R} \$ 1,00 \mathrm{~kg}^{-1}\right)$, a lâmina economicamente ótima foi estimada em 244,2 $\mathrm{mm}$ resultando em uma produtividade comercial praticamente semelhante à máxima física.

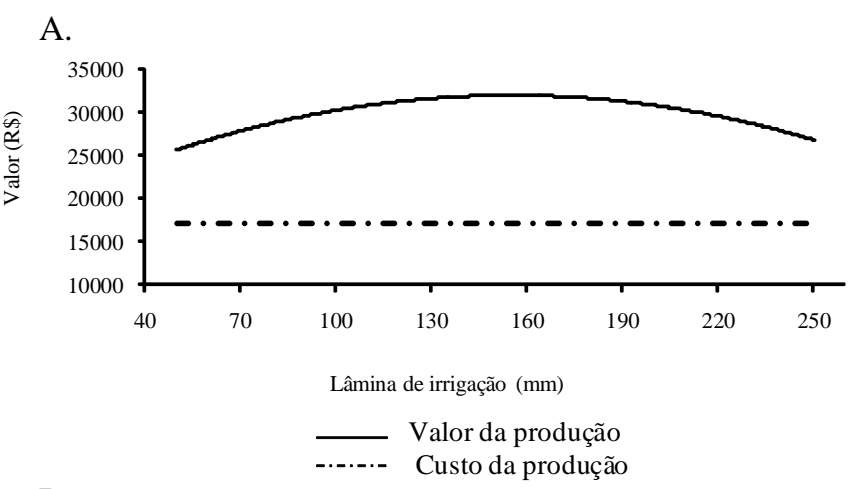

B.

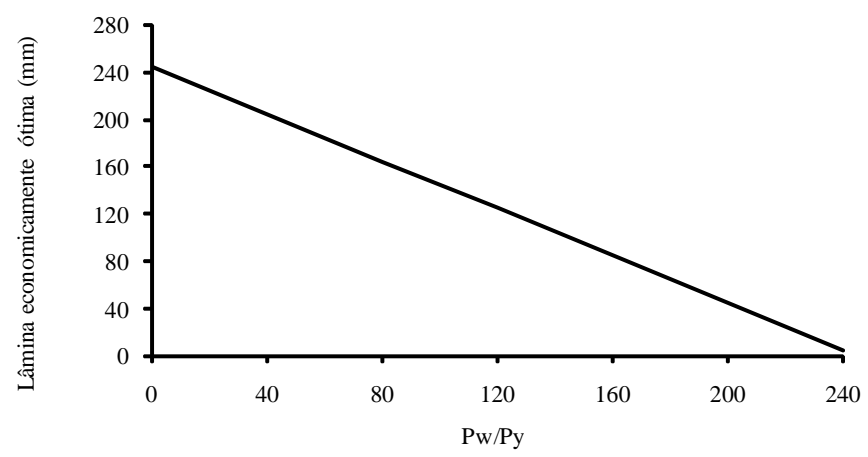

Figura 2. Custo e valor da produção $(A)$ e lâmina total de água economicamente ótima (B), em função da relação entre o preço da água e o preço da alface

Fazendo uma análise comparativa entre a lâmina ótima que traduz a eficiência econômica e a que gera a produtividade física máxima (eficiência técnica), observam-se valores aproximadamente iguais; logo, ao se aplicar uma lâmina de água que proporcione a máxima produção física, tem-se que ela será suficiente para alcançar uma produção economicamente viável. Esta aproximação se deve sobretudo ao tipo de sistema de irrigação que está sendo utilizado de vez que, como se trata de um sistema de irrigação localizado que se caracteriza por trabalhar com baixa pressão e vazão, possivelmente proporcionará valores reduzidos do preço do fator água; este resultado ainda indica que a irrigação deve ser feita de forma a garantir o máximo desenvolvimento vegetativo da cultura, sob ótimas condições de umidade de solo.

Visando atender às diferentes relações $\mathrm{Pw} / \mathrm{Py}$, confeccionou-se uma tabela dos valores de lâmina total de água ótima em função da relação de preços entre fator água e do produto alface (Pw/Py), (Figura 2). Verifica-se que a lâmina ótima decresce à medida em que se aumenta a relação entre preços (Pw/Py); assim, considerando-se esta tendência e variando o preço da água e mantendo fixo o da alface, a lâmina econômica total de irrigação a se aplicar deve ser menor em virtude do custo da água, para que o produtor obtenha a rentabilidade máxima da atividade em estudo.

\section{CONCLusÕES}

1. A máxima produtividade total e comercial, 65.918 e 35.544 $\mathrm{kg} \mathrm{ha}^{-1}$, foi estimada com a aplicação de lâminas equivalentes a 152,1 e $155 \mathrm{~mm}$, respectivamente, correspondente ao fator de reposição de $92 \%$.

2. Considerando o preço do fator água $\left(\mathrm{R} \$ 0,67 \mathrm{~mm}^{-1}\right)$ e o preço da alface americana $\left(\mathrm{R} \$ 0,90 \mathrm{~kg}^{-1}\right)$, a lâmina economicamente ótima foi $154 \mathrm{~mm}$, identificando que a eficiência técnica do experimento foi significativamente igual à máxima eficiência econômica.

\section{LITERATURA CITADA}

Agrianual - Anuário da Agricultura Brasileira: Alface. São Paulo: FNP, 2008. 345p.

Algozin, K. A.; Bralts, V. F.; Ritchie, J. T. Irrigation strategy selection based on crop yield, water, and energy use relationships: A Michigan example. Journal of Soil and Water Conservation, v.10, p.428-31. 1988.

Andrade Júnior, A. S. de; Klar, A. E. Manejo da irrigação da cultura da alface (Lactuca sativa L.) através do tanque classe A. Scientia Agricola, v.54, p.31-38, 1997.

Dantas, A. A. A.; Carvalho, L. G.; Ferreira, E. Classificação e tendência climática em Lavras, MG. Ciência e Agrotecnológia, v.31,p.1862-1866, 2007.

Filgueira, F. A. R. Novo manual de olericultura: Agrotecnologia moderna na produção e comercialização de hortaliças. 3.ed. Viçosa: UFV, 2008. 421p.

Koetz, M.; Coelho, G.; Costa, C. C. C.; Lima, E. P.; Souza, R. J. Efeito de doses de potássio e da frequiência de irrigação na produção da alface-americana em ambiente protegido. Engenharia Agrícola, v.26, p.730-737, 2006.

Lima Júnior, J. A.; Pereira, G. M.; Geisenhoff, L. O.; Costa, G. G.; Vilas Boas, R. C.; Yuri, J. E. Efeito da irrigação sobre o efeito produtivo da alface americana, em cultivo protegido. Revista Brasileira de Engenharia Agrícola e Ambiental, v.14, p.797803, 2010.

Oliveira, A. C. B.; Sediyama, M. A. N.; Pedrosa, M. W.; Garcia, N. C. P.; Garcia, S. L. R. Divergência genética e descarte de variáveis em alface cultivada sob sistema hidropônico. Acta Scientiarum, v.26, p.211-217, 2004.

Santana, C. V. S.; Almeida, A. C.; Turco, S. H. N. Produção de alface roxa em ambientes sombreados na região do Submédio São Francisco - BA. Revista Verde de Agroecologia e Desenvolvimento Sustentável, v.4, p.1-6, 2009. 
Santos, S. R.; Pereira, G. M. Comportamento da alface tipo americana sob diferentes tensões da água no solo, em ambiente protegido. Engenharia Agrícola, v.24, p.569-577, 2004.

Segovia, J. F. O.; Andriolo, J. L.; Buriol, G. A.; Schneider, F. M. Comparação do crescimento e desenvolvimento da alface (Lactuca sativa L.) no interior e exterior de uma estufa de polietilenoem Santa Maria-RS. Ciência Rural, v.27, p.37-41, 1997.

Silva, P. A. M.; Pereira, G. M.; Reis, R. P.; Lima, L. A.; Taveira, J. H. S. Função de resposta da alface americana aos níveis de água e adubação nitrogenada. Ciência e Agrotecnológia, v.32, p.1266-1271, 2008.

Vasconcellos, M. A. S. de. Fundamentos de economia. 2 ed.São Paulo: Saraiva, 2007. 246p.
Vilas-Boas, R. C.; Carvalho, J. A.; Gomes, L. A. A.; Sousa, A. M. G.; Rodrigues, R. C.; Souza, K. J. Avaliação técnica e econômica da produção de duas cultivatires de alface ti crespa em função de lâminas de irrigação. Ciência e Agrotecnológia, v.32, p. 525-531, 2008.

Yuri, J. E.; Mota, J. H.; Resende, G. M.; Souza, R. J.; Rodrigues Júnior, J. C. Desempenho de cultivares de alface tipo americana em cultivo de outono no sul de minas gerais. Ciência e Agrotecnologia, v.28, p.282-286, 2004.

Yuri, J. E.; Souza, R. J. de; Freitas, S. A. C. de; Rodrigues Júnior, J. C.; Mota, J. H. Comportamento de cultivares de alface tipo americana em Boa esperança. Horticultura Brasileira, v.20, p.229-232, 2002. 